\title{
Influence of breastfeeding duration on the incidence of dental caries in preschoolers: a cohort study
}

Heloísa Helena Barroso 1

(iD https://orcid.org/0000-0003-4746-8244

Priscila Seixas Mourão 2

(iD https://orcid.org/0000-0002-5309-9249

Rafaela Lopes Gomes 3

iD https://orcid.org/0000-0002-8775-730X

Maria Tereza Pereira de Almeida 4

iD https://orcid.org/0000-0001-5204-8207

\author{
Thaís Santos Silva 5 \\ iD https://orcid.org/0000-0002-8000-3337 \\ Joana Ramos-Jorge 6 \\ (iD) https://orcid.org/0000-0003-1906-3784 \\ Maria Letícia Ramos-Jorge 7 \\ iD https://orcid.org/0000-0001-8495-9259 \\ Izabella Barbosa Fernandes 8 \\ (iD) https://orcid.org/0000-0003-4869-9925
}

1-5,7 Departamento de Odontologia. Universidade Federal dos Vales do Jequitinhonha e Mucuri. Campus I. Rua da Glória, 187. Centro. Diamantina, MG, Brasil. E-mail: priscila.smourao@gmail.com

6,8 Departamento de Saúde Bucal da Criança e do Adolescente. Faculdade de Odontologia. Universidade Federal de Minas Gerais. Belo Horizonte, MG, Brasil.

\begin{abstract}
Objectives: investigate the association between breastfeeding duration and the incidence of severe caries in preschoolers.

Methods: a cohort study was conducted with 132 pairs of mothers and children in the city of Diamantina, Brazil. Data collection was performed in 2 moments: when the children were between two and three years of age (baseline- 2013/2014) and after three years (T12016/2017). In both moments, children were evaluated for dental caries (International Caries Detection and Assessment System - ICDAS) and a questionnaire was administered to the mothers addressing socioeconomic aspects and thee habits of children. The outcome evaluated was the incidence of severe caries (Dentin caries - ICDAS Codes 5 and 6). Data analysis involved descriptive statistics, chi-squared test and Poisson hierarchical regression with robust variance.

Results: children who breastfed for more than 24 months $(R R=2.24 C 195 \%=1.23-4.08)$, those whose parents were separated $(R R=1.73 C 195 \%=1.11-2.69)$, and those with established/severe caries $(R R=2.74 C 195 \%=1.37-5.49)$ at baseline were at greater risk of incidence of severe caries after three years.

Conclusion: breastfeeding for more than 24 months is a risk factor for incidence of severe caries. In addition, family structure and established or severe baseline caries were associated.

Key words Dental caries, Breast-feeding, Oral health, Longitudinal studies
\end{abstract}

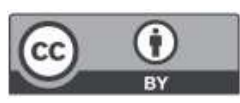




\section{Introduction}

Dental caries is a common chronic disease in childhood and highly prevalent throughout the world. Prevention and control of dental caries in primary teeth is challenging and this condition is considered a public health problem due to the high costs for society as well as the negative impact on the quality of life of affected children and their families. ${ }^{2}$

Breastmilk has all the components necessary to meet the nutritional and immunological needs of infants. 3 The act of breastfeeding also has benefits in terms of emotional aspects, health, growth, learning and the development of the functions of the stomatognathic system. 3,4 Moreover, breastfeeding offers health benefits for the mother, such as a greater spacing between childbirths as well as a lower risk of type 2 diabetes, breast cancer and ovarian cancer.3,5,6 The World Health Organization 7 (WHO) and health authorities recommend that all infants be breastfed exclusively until six months of age, followed by the continuation of breastfeeding up to two years of age or more, complemented with other foods. Despite the benefits of breastfeeding, concerns have been raised regarding the impact of prolonged breastfeeding on the occurrence of dental caries. ${ }^{8,9}$ However, there is limited evidence on this issue, as many of the studies investigating the association failed to control for confounding factors, such as food intake and oral hygiene. A prospective cohort study is the most adequate design for the determination of associations. 10

Recent systematic review investigating the influence of prolonged breastfeeding on the occurrence of dental caries emphasize the need for further, wellplanned, longitudinal studies that control for relevant confounding factors. ${ }^{11}$ Investigating the association between prolonged breastfeeding and dental caries is of extreme importance, as the findings could contribute to national policies on infant and reduce the occurrence of caries in primary teeth. Considering the hypothesis that prolonged breastfeeding for more than 24 months may be associated with a higher incidence of severe caries, the aim of the present study was to investigate the association between breastfeeding duration and the incidence of dental caries in preschoolers.

\section{Methods}

This study received approval from the Human Research Ethics Committee of the Federal University of Vales do Jequitinhonha e Mucuri (UFVJM - Portuguese acronym), Brazil (certificate number: 1.921.084). All parents received clarifications regarding the objectives of the study and signed a statement of informed consent. The recommendations of the Strengthening the Reporting of Observational Studies in Epidemiology (STROBE statement) were used to guide the study and draft the manuscript.

The present three-year cohort study was nested in a previously published cross-sectional study. 12 The first study was conducted with a sample of 308 children selected randomly from National Child Vaccination Program list (2013 - 2014), provided by the municipal health department of Diamantina (baseline). Vaccination coverage rates in 2013 and 2014 were $97.00 \%$ and $102.19 \%$, respectively. 13 The sample size calculation for the longitudinal study was performed based on the results of the pilot study and considering a $5 \%$ standard error, $95 \%$ confidence interval and $73 \%$ incidence of caries among the exposed participants (breastfeeding for more than two years). A minimum of 62 children were needed for each group, to which $10 \%$ was added (seven children per group) to compensate for possible dropouts, totaling 138 children (69 in each group). The children included in the longitudinal study were selected by drawing according to the exposure factor (breastfeeding for more than two years). Thus, two groups were formed: children who breastfed for more than two years and children who were breastfed for up to two years.

Children with systemic diseases, such as cancer, respiratory diseases or other adverse health conditions that would interfere with the results were excluded. Moreover, the mother needed to be the main caregiver. Children not accompanied by their mothers during the data collection process were excluded from study.

Two examiners underwent training and calibration exercises prior to the examinations and pilot study. The training portion involving theoretical explanations and the analysis of images of different clinical situations of dental caries. For the calibration portion, the examiners and an experienced researcher performed clinical examinations of 30 children on two separate occasions separated by a one-week interval. The minimum Kappa coefficient was 0.85 for intra-examiner agreement and 0.86 for inter-examiner agreement.

In the first phase of the study (baseline), in the years 2013 and 2014, the selected mothers and children were asked to visit the pediatric dentistry clinic of the Federal University of Vales do Jequitinhonha e Mucuri for data collection.

Clinical data were collected with the child seated 
on a children's dental stretcher, and mothers kept very young children when needed. The clinical exams were performed under artificial light following prophylaxis. All care with biosafety was taken as using personal protective equipment for the dentist and child and using sterile instruments.

Dental caries was diagnosed using the International Caries Detection and Assessment System (ICDAS). 14 The dental surfaces were first examined wet and examined a second time after drying with compressed air for five seconds. All surfaces were examined and classified as initial caries (ICDAS codes 1 or 2), established caries (ICDAS codes 3 or 4 ) or severe caries (ICDAS codes 5 or 6$)$.

Non-clinical data were collected using a questionnaire administered to the mothers in interview form. An independent researcher applied the questionnaire to the mothers. The questionnaire addressed socioeconomic characteristics, such as parents' schooling [13 or more years of study (university education); ten to 12 years (high school); less than ten years (elementary school/middle school)],family income [using the Brazilian monthly minimum wage as reference $(B M M W=R \$ 724$ at the time of the study) and dichotomized by median as $>$ two times the BMMW or $<$ two times the BMMW], number of individuals who live on this income (one to three; four or five; six or more - categorized by tertiles) and family structure [nuclear (parents live together); non-nuclear (divorced parents)]. Data were also collected on children's characteristics (sex and age in months) and the following habits: breastfeeding duration categorizes according to the breastfeeding period recommended by WHO8 (up to two years or more than two years), bottle feeding duration (up to two years or more than two years), and whether the child's oral hygiene was performed by an adult (yes or no).

Data collection on food intake was performed by applying a food consumption frequency questionnaire. 15 The questionnaire consisted of 23 foods, with 15 possibilities of response to consumption: daily (one, two, three, four or five times a day); weekly (six, five, four, three, two or once a week); biweekly; monthly; rare and never. Frequency of habitual consumption of chocolate, candies, lollipops, soda and chewing gum was compiled into a single sugar consumption group and categorized according to the daily consumption frequency: "low sugar consumption" ( 0 or $<$ Twice a day) and "high sugar consumption" ( $\geq 2$ times a day). 16

All mothers received counseling on the oral health of the children and those with treatment needs were referred to the pediatric dentistry clinic of the Federal University of Vales do Jequitinhonha e Mucuri.

Three years after baseline (T1) (2016 and 2017), the participants were contacted by telephone or home visits to schedule the reevaluations at the pediatric dentistry clinic of the Federal University of Vales do Jequitinhonha e Mucuri. The same examiners underwent training and calibrations exercises again prior to the reevaluation of the children. Children who participated in the calibration process were not included in the sample. The minimum Kappa coefficient was 0.86 for intra-examiner agreement and 0.86 for inter-examiner agreement.

A pilot study was conducted with 30 children to obtain results for the calculation of the follow-up sample. As no changes were made to the methods, the children in pilot study were included in the main study.

The children were submitted to new oral clinical examinations for the evaluation of dental caries using the same criteria employed at the baseline evaluation. The incidence of severe caries was recorded when a child had new severe caries that were not present at baseline (incidence of severe caries - yes or no). The same questionnaire used at baseline was also administered to the mothers again. Data analysis was performed using the Statistical Package for the Social Sciences (SPSS para Windows, version 22.0, SPSS Inc., Chicago, USA) and involved descriptive analysis. Comparisons of the baseline characteristics of those lost and those followed up were performed using chi-square test and Cohen's effect size (w) was also calculated. The chi-squared test was used to compare proportions of socioeconomic characteristics, child's characteristics, child's habits and clinical aspects, according the incidence of severe caries. Univariate and multiple Poisson regression analyses with robust variance using a hierarchical approach. For such, the variables were grouped into distal to proximal determinants. The categories were socioeconomic factors, child's characteristics, child's habits and clinical factors (in that order) (Figure 1). Poisson regression analysis with robust variance was performed for each level. Only explanatory variables with a $p$ value $\leq 0.20$ were selected for the multivariate analysis. Explanatory variables with a $p$-value $<0.05$ after adjustments for variables on the same or previous levels were selected for the final model. Relative risk (RR) and respective $95 \%$ confidence intervals (CI) were calculated. In addition, the main independent variable (duration of breastfeeding) was adjusted for each independent variable in another 
analysis model.

\section{Results}

A total of 132 children (95.6\%) participated through to the end of the study. The main reasons for dropouts were the change of address and change of telephone number (Dropouts: 6 children $=4.4 \%$ ) (Figure 1). Mean age $34.9 \pm 9.5$ months at baseline was $69.1 \pm 7.2$ months at the follow-up evaluation. Among the children evaluated, 53.0\% were girls. The incidence of severe caries was $33.3 \%$. All children had access to fluoridated water and used fluoride toothpastes $(\geq 1000 \mathrm{ppm})$ at both baseline and follow-up. Table 1 shows baseline characteristics between follow-up and dropout participants. There were no differences between children who remained in the study and those who were lost during the follow-up. The magnitude of the statistical difference (Cohen's effect size) was small.

Table 2 presents the descriptive data of the sample and comparison of proportions of socioeconomic factors, child's characteristics, child's habits and clinical aspects, according to the incidence of severe caries. There were statistically significant associations between the incidence of severe caries and breastfeeding duration and the baseline variables: dependent on family income, family structure, age and dental caries at baseline.

In the multivariate analysis (Table 3 ), children who breastfed for more than 24 months ( $R R=2.24$ CI95\% $=1.23$ to 4.08 ), those who lived with separated parents at baseline $(\mathrm{RR}=1.73 \mathrm{CI95 \%}=1.11$ to $2.69)$, those with initial caries at baseline $(\mathrm{RR}=2.14$ $\mathrm{CI} 95 \%=1.06$ to 4.31$)$ and those with established/severe caries at baseline $(\mathrm{RR}=2.74$ $\mathrm{CI} 95 \%=1.37$ to 5.49 ) were at greater risk of the incidence of severe caries at follow-up.

Breastfeeding for more than 24 months remained significantly associated with the incidence of severe caries after the adjustments by levels (Table 3 ) and after the adjustment of each variable individually (Table 4).

\section{Discussion}

The present study investigated the association between prolonged breastfeeding and severe caries in preschoolers. This study highlighted the incidence of severe caries (ICDAS 5 and 6), due to its potential to impact children's quality of life. 12 The main findings demonstrate that children who were breastfed for more than 24 months were at greater risk of the incidence of severe dental caries indepen- dently of sugar intake or oral hygiene.

These findings are supported by recent evidence affirming an association between breastfeeding duration and dental caries.9,16 However, few of these studies had a prospective design or controlled for important determinant factors, such as diet and oral hygiene. 16,17 Some studies report that breastfeeding up to 12 months of age is a protective factor against the occurrence of caries. 17 Other studies report a greater risk of caries when breastfeeding is performed for a longer period of time (12 to 24 months) as well as when breastfeeding is performed at night and with a high frequency. 8,16 According to the World Health Organization 7 the minimum period for complementary breastfeeding is 24 months, which is why this period was adopted as the cutoff point in the present study. Studies that have used the same cutoff point confirm our findings. 9,16

The plausibility of this association may reside in the bioavailability of breastmilk and its nutritional composition, as mature breastmilk is composed of approximately $7 \%$ sugars. ${ }^{8}$ In vitro and in situ studies have shown that human milk has the potential to induce the demineralization of tooth enamel and supplementation with sugar exponentially enhances its cariogenic potential. 18,19,20 The cariogenic potential of breastmilk is reported to be higher than that of bovine milk, but lower than that found in baby formulas. 21

Important factors that should be taken into consideration are breastfeeding frequency and timing. The lack of an investigation of these variables is a limitation of the present study. Frequent breastfeeding can increase the cariogenic potential; breastfeeding at night also has this effect due to the reduction in salivary flow during sleep. ${ }^{22}$ Studies have shown an association between breastfeeding and dental caries when the feeding pattern is established by free demand with successive feedings during the day, long feeding periods and frequent nighttime feeding, causing the buildup of milk on the surface of the teeth, which, together with the reduction in salivary flow and inadequate oral hygiene, can lead to the emergence of caries. 23

The risk of the incidence of severe caries was greater among children who lived in a non-nuclear family (separated parents). This finding is in agreement with the results of studies investigating determinants of early childhood caries. 24 Family structure is considered an important determinant of oral health status in children. 25 As children are dependent on their parents for the control of diet and hygiene, 26 it is possible that single parents have greater difficulty maintaining the oral health of their children due to 


\section{Figure 1}

Hierarchical conceptual framework used in the Poisson regression analysis.

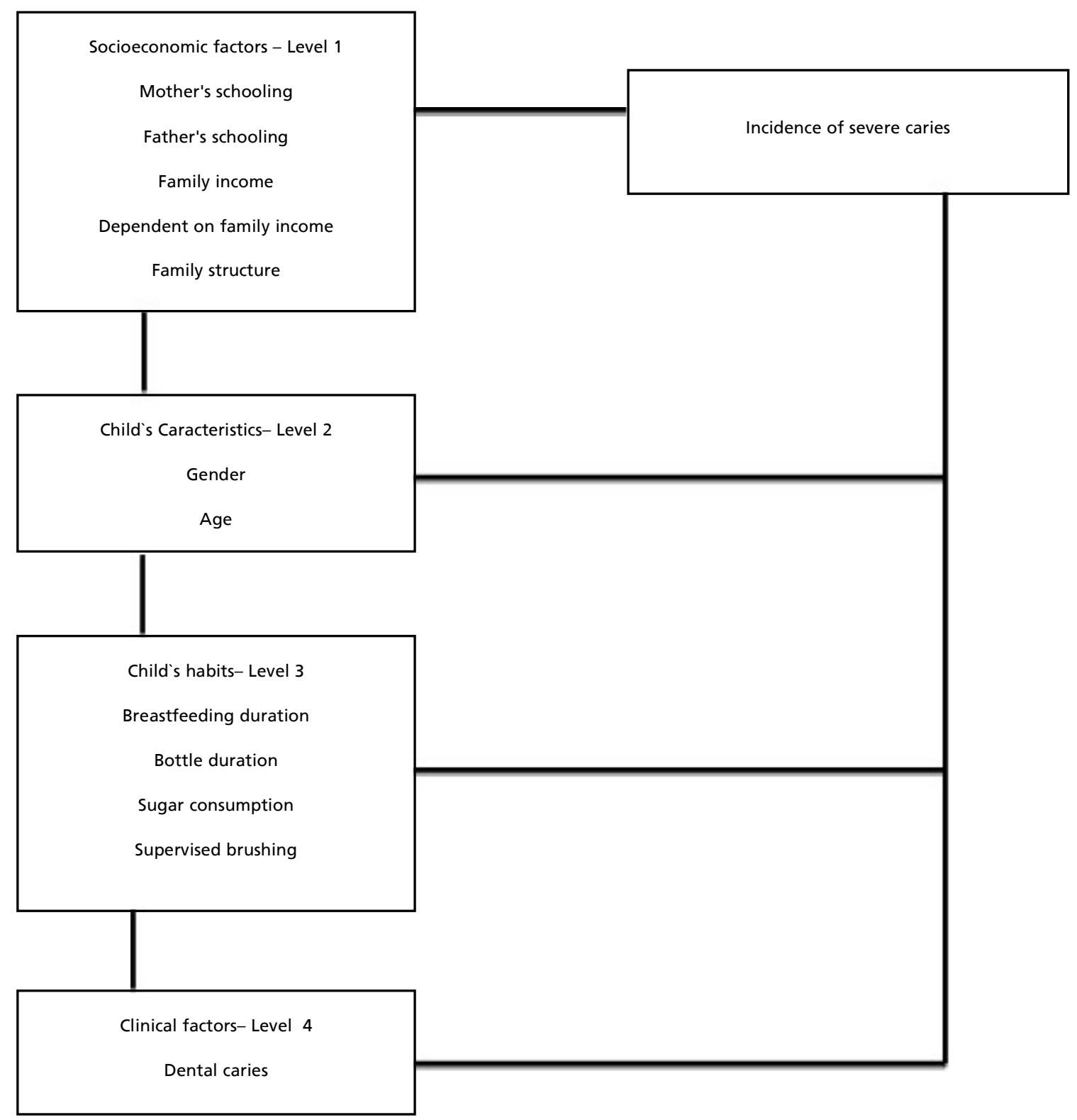


Table 1

\begin{tabular}{|c|c|c|c|c|c|c|}
\hline \multirow[t]{2}{*}{ Variables } & \multicolumn{2}{|c|}{ Follow-ups } & \multicolumn{2}{|c|}{ Dropouts } & \multirow[t]{2}{*}{ Cohen's effect size ${ }^{* *}$} & \multirow[t]{2}{*}{$p^{*}$} \\
\hline & $\mathrm{n}$ & $\%$ & $\mathrm{n}$ & $\%$ & & \\
\hline Mother's schooling (years) & & & & & 0.030 & 0.729 \\
\hline$\geq 13$ & 47 & 35.6 & 2 & 33.3 & & \\
\hline $10-12$ & 72 & 54.5 & 3 & 50.0 & & \\
\hline $0-9$ & 13 & 9.9 & 1 & 16.7 & & \\
\hline Father's schooling (years) & & & & & 0.036 & 0.670 \\
\hline$\geq 13$ & 32 & 24.2 & 1 & 16.7 & & \\
\hline $10-12$ & 63 & 47.7 & 3 & 50.0 & & \\
\hline $0-9$ & 37 & 28.0 & 2 & 33.3 & & \\
\hline Family income (minimum wage) & & & & & 0.038 & 0.660 \\
\hline$\geq 2$ & 56 & 42.4 & 2 & 33.3 & & \\
\hline$<2$ & 76 & 57.6 & 4 & 66.7 & & \\
\hline \multicolumn{7}{|l|}{ Dependent on family income } \\
\hline (individuals) & & & & & 0.009 & 0.916 \\
\hline 1 to 3 & 41 & 31.1 & 2 & 33.3 & & \\
\hline 4 or 5 & 68 & 51.5 & 3 & 50.0 & & \\
\hline 6 or more & 23 & 17.4 & 1 & 16.7 & & \\
\hline Family structure & & & & & 0.039 & 1.000 \\
\hline Nuclear & 78 & 73.6 & 5 & 83.3 & & \\
\hline Non-nuclear & 28 & 26.4 & 1 & 16.7 & & \\
\hline Gender & & & & & 0.022 & 1.000 \\
\hline Female & 73 & 55.3 & 3 & 50.0 & & \\
\hline Male & 59 & 44.7 & 3 & 50.0 & & \\
\hline Age (years old) & & & & & 0.016 & 0.851 \\
\hline 2 & 83 & 62.9 & 4 & 66.7 & & \\
\hline 3 & 49 & 37.1 & 2 & 33.3 & & \\
\hline Sugar consumption & & & & & 0.012 & 1.000 \\
\hline Low consumption & 70 & 53.0 & 3 & 50.0 & & \\
\hline High consumption & 62 & 47.0 & 3 & 50.0 & & \\
\hline Supervised brushing & & & & & 0.008 & 1.000 \\
\hline Yes & 108 & 81.8 & 5 & 83.3 & & \\
\hline No & 24 & 18.2 & 1 & 16.7 & & \\
\hline Dental caries & & & & & 0.041 & 0.633 \\
\hline Absence of caries & 59 & 44.7 & 3 & 50.0 & & \\
\hline Initial caries & 36 & 27.3 & 2 & 33.3 & & \\
\hline Established/severe caries & 37 & 28.0 & 1 & 16.7 & & \\
\hline
\end{tabular}

* Chi-square test; ** Effect size based on Cohen's w: 0.1 for small; 0.3 for medium; 0.5 for large. 
Descriptive data of the sample and comparison of proportions of socioeconomic characteristics, child's characteristics, child's habits and clinical factors, according the incidence of severe caries.

\begin{tabular}{|c|c|c|c|c|c|}
\hline & \multicolumn{4}{|c|}{ Incidence of severe caries } & \multirow[t]{3}{*}{$p^{*}$} \\
\hline & \multicolumn{2}{|c|}{ No } & \multicolumn{2}{|c|}{ Yes } & \\
\hline & $\mathrm{n}$ & $\%$ & $\mathrm{n}$ & $\%$ & \\
\hline \multicolumn{6}{|l|}{ Socioeconomic variables } \\
\hline Mother's schooling at baseline (years) & & & & & $0.062 *$ \\
\hline$\geq 13$ & 37 & 78.7 & 10 & 21.3 & \\
\hline $10-12$ & 43 & 59.7 & 29 & 40.3 & \\
\hline $0-9$ & 8 & 61.5 & 5 & 38.5 & \\
\hline Father's schooling at baseline (years) & & & & & $0.107^{*}$ \\
\hline$\geq 13$ & 26 & 81.3 & 6 & 18.8 & \\
\hline $10-12$ & 39 & 61.9 & 24 & 38.1 & \\
\hline $0-9$ & 23 & 62.2 & 14 & 37.8 & \\
\hline Family income at baseline (minimum wages) & & & & & $0.059 *$ \\
\hline$\geq 2$ & 42 & 75.0 & 14 & 25.0 & \\
\hline$<2$ & 46 & 60.5 & 30 & 39.5 & \\
\hline \multicolumn{6}{|l|}{ Dependent on family income at baseline } \\
\hline (individuals) & & & & & $0.031 *$ \\
\hline 1 to 3 & 25 & 61.0 & 16 & 39.0 & \\
\hline 4 or 5 & 42 & 61.8 & 26 & 38.2 & \\
\hline 6 or more & 21 & 91.3 & 2 & 8.7 & \\
\hline Family structure at baseline & & & & & $0.011 *$ \\
\hline Nuclear & 72 & 72.7 & 27 & 27.3 & \\
\hline Non-nuclear & 16 & 48.5 & 17 & 51.5 & \\
\hline \multicolumn{6}{|l|}{ Characteristics of the child } \\
\hline Gender & & & & & $0.173 *$ \\
\hline Female & 45 & 61.6 & 28 & 38.4 & \\
\hline Male & 43 & 72.9 & 16 & 27.1 & \\
\hline \multicolumn{6}{|l|}{ Age at baseline (months) } \\
\hline Average (DP) & $33.3(8.6)$ & & $37.9(10.3)$ & & 0.014 ** \\
\hline \multicolumn{6}{|l|}{ Child's habits } \\
\hline Breastfeeding duration (months) & & & & & $<0.001 *$ \\
\hline Up to 24 & 55 & 83.3 & 11 & 16.7 & \\
\hline More than 24 & 33 & 50.0 & 33 & 50.0 & \\
\hline Bottle duration (months) & & & & & $0.448 *$ \\
\hline Up to 24 & 52 & 64.2 & 29 & 35.8 & \\
\hline More than 24 & 36 & 70.6 & 15 & 29.4 & \\
\hline Sugar consumption at baseline & & & & & $0.388^{*}$ \\
\hline Low consumption & 49 & 70.0 & 21 & 30.0 & \\
\hline High consumption & 39 & 62.9 & 23 & 37.1 & \\
\hline Supervised brushing at baseline & & & & & $0.632 *$ \\
\hline Yes & 73 & 67.6 & 35 & 32.4 & \\
\hline No & 15 & 62.5 & 9 & 37.5 & \\
\hline Clinical factors & & & & & $<0.001$ * \\
\hline \multicolumn{6}{|l|}{ Dental caries at baseline } \\
\hline Absence of caries & 50 & 84.7 & 9 & 15.3 & \\
\hline Initial caries & 23 & 63.9 & 13 & 36.1 & \\
\hline Established/severe caries & 15 & 40.5 & 22 & 33.3 & \\
\hline
\end{tabular}

* Chi-square test; ** Mann-Whitney Test. 


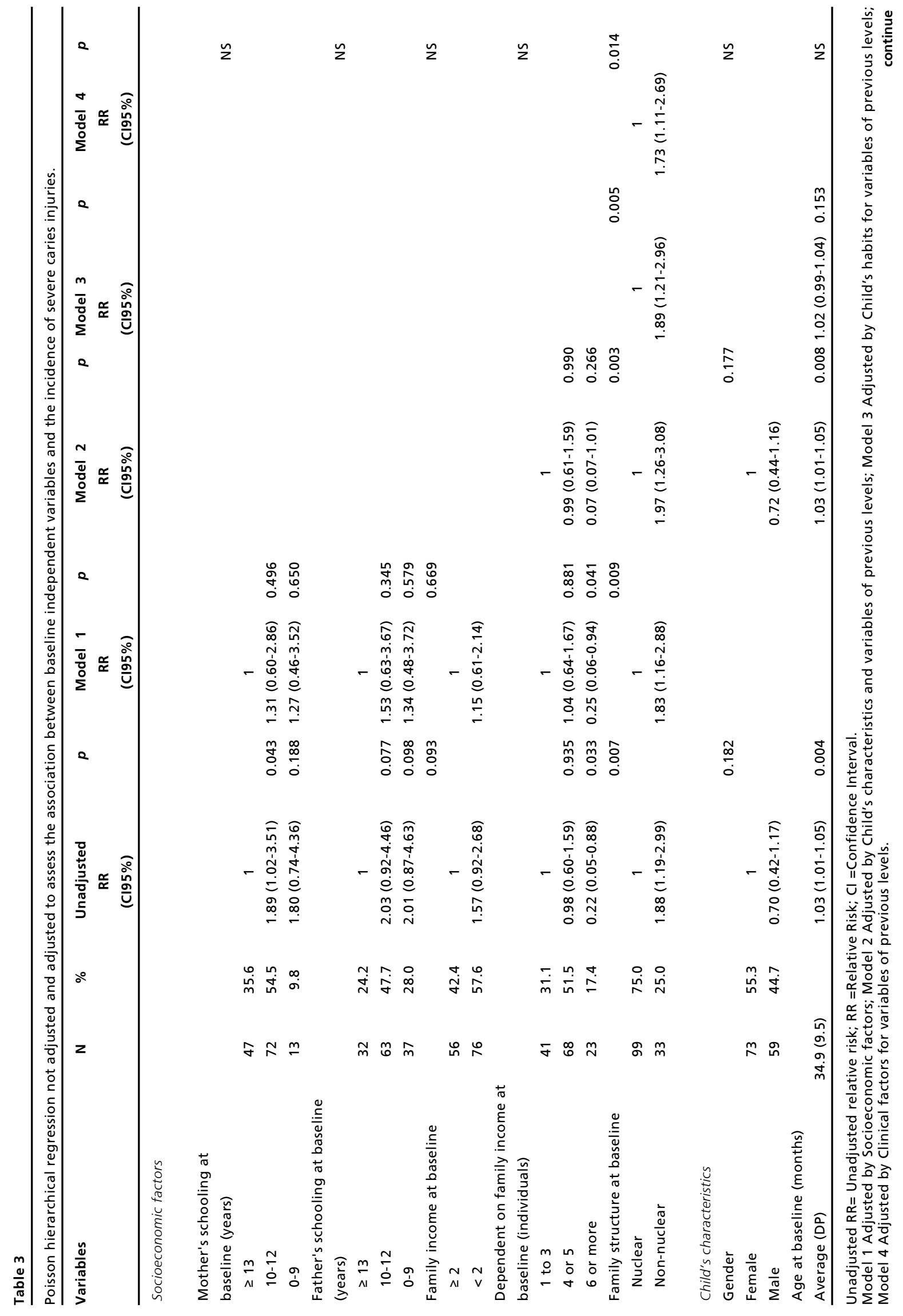




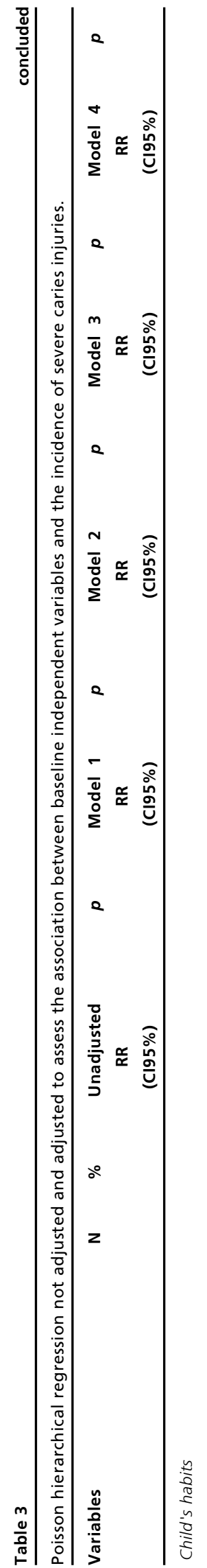

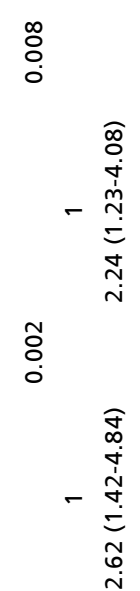

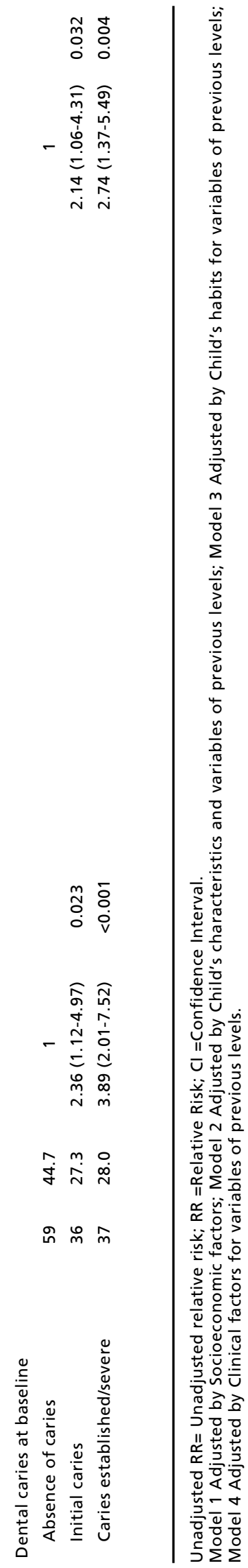

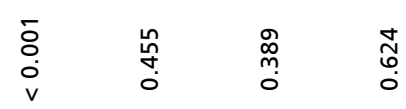

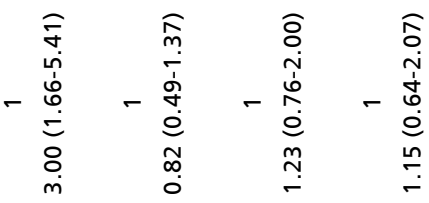

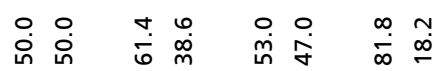

유 历̄

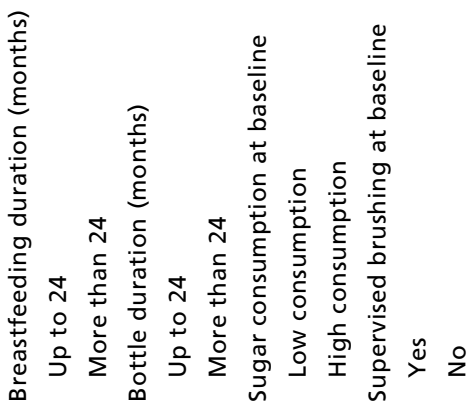

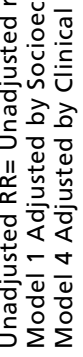


Unadjusted Poisson regression model adjusted for breastfeeding at 24 months and sociodemographic variables, bottle use, sucrose intake, and dental caries at baseline.

\begin{tabular}{lcc}
\hline $\begin{array}{l}\text { Breastfeeding up to } 24 \text { months (reference) } \\
\text { Breastfeeding for more than } \mathbf{2 4} \text { months }\end{array}$ & RR (CI95\%) & $p$ \\
\hline Unadjusted & $3.00(1.66-5.41)$ & $\leq 0.001$ \\
Adjusted for sex & $2.94(1.63-5.31)$ & $\leq 0.001$ \\
Adjusted for age & $2.69(1.43-5.07)$ & 0.002 \\
Adjusted for mother's schooling & $2.83(1.53-5.22)$ & $\leq 0.001$ \\
Adjusted for father's schooling & $2.81(1.49-5.30)$ & 0.001 \\
Adjusted for family income & $2.86(1.53-5.34)$ & 0.001 \\
Adjusted for dependent on family income & $2.93(1.66-5.19)$ & $\leq 0.001$ \\
Adjusted for family structure & $2.97(1.67-5.28)$ & $\leq 0.001$ \\
Adjusted for tooth brushing & $3.04(1.68-5.51)$ & $\leq 0.001$ \\
Adjusted for bottle & $3.01(1.65-5.49)$ & $\leq 0.001$ \\
Adjusted for sugar consumption & $3.05(1.72-5.42)$ & $\leq 0.001$ \\
Adjusted for dental caries at baseline & $2.27(1.23-4.21)$ & 0.009 \\
Adjusted for all variables & $2.17(1.21-3.88)$ & 0.009
\end{tabular}

$\mathrm{RR}=$ Relative Risk; $\mathrm{Cl}=$ Confidence Interval.

the impossibility of sharing tasks and the less time available for meeting care needs. However, other social determinants, such as parental education and family income, did not remain associated with the incidence of severe caries during follow-up as expected. The association between socioeconomic characteristics and dental caries were showed in many studies. 27 Although these variables were included in the multivariate analysis, they were not associated with the incidence of caries after adjustment for other factors, thus indicating that in this sample, proximal determinants have a greater explanatory effect for an increase in caries.

Some expected associations were not found in the present study, such as the association between the incidence of severe caries and sugar intake or supervised tooth brushing. The effect of these variables on the incidence of caries may have been attenuated by the access that all children had to fluoride in both drinking water and toothpastes. Studies have demonstrated that exposure to fluoride attenuates the cariogenic effect of a diet rich in sugar. 28 Moreover, it has been reported that the daily use of a fluoride toothpaste seems to be more important than the emphasis on the complete removal of bacterial plaque. 29

However, access to fluoride did not exert an influence on the association between breastfeeding duration and dental caries. In contrast to the present findings, a recent study 30 investigated the effect of exposure to fluoridated water on the association between breastfeeding duration and caries and concluded that early life exposure to fluoridated drinking water attenuated the potential cariogenic effect of the lack of breastfeeding or prolonged breastfeeding (more than 24 months).

In conclusion, the results show that breastfeeding for more than 24 months was a risk factor for the incidence of severe dental caries in the population studied, as well as other factors such as the presence of caries in the first two years of life and non-nuclear family structure. It is important to exercise caution when extrapolating the results found in the present study because some important variables such as the frequency of breastfeeding and the habit of breastfeeding at night were not statistically controlled in the present study. The present results highlight the importance of health education focused on children at tender age and can be used for the establishment of educational and preventive measures, always seeking balance between the benefits and inherent risks of the attitudes adopted. Together with such measures, dentists, pediatricians and nutritionists should encourage breastfeeding in accordance with the recommendations of the World Health Organization, ${ }^{7}$ given the benefits of this practice regarding the health of children. Counseling should be based on the individual risk of each patient and in accordance with the values and circumstances of his/her family. 


\section{Author's contribution}

Barroso HH, Mourão PS and Ramos-Jorge J participated in the elaboration and critical review of the study's intellectual content. Gomes RL, Almeida MTP, Silva TS performed research planning, study design, acquisition and analysis of study data, bibli-

\section{References}

1. GBD 2016 Incidents of Incidence and Prevalence of Disease and Injury. Global, regional and national incidence, prevalence and disability-lived years for 328 diseases and injuries in 195 countries, 1990-2016: A Systematic Analysis for the 2016 Global Disease Burden Study. Lancet. 2017 16; 390 (10100): 1211-59.

2. Tinanoff N, Baez RJ, Diaz Guillory C, Donly KJ, Feldens CA, McGrath C, Phantumvanit P, Pitts NB, Seow WK, Sharkov N, Songpaisan Y, TwetmanS. Early childhood caries epidemiology, aetiology, risk assessment, societal burden, management, education, and policy: Global perspective. Int J Paediatr Dent. 2019; 29 (3): 238-48.

3. Victora CG, Bahl R, Barros AJ, França GV, Horton S, Krasevec J, Murch S, Sankar MJ, Walker N, Rollins NC Lancet Breastfeeding Series Group. Breastfeeding in the 21st century: epidemiology, mechanisms, and lifelong effect. Lancet. 2016; 387 (10017): 475-90

4. Bervian J, Fontana M, Caus B. Relationship among breastfeeding, oral motor development and oral habits - literature review. RFO. 2008; 13 (2): 76-81.

5. Aune D, T Norat, Romundstad P, Vatten LJ. Breastfeeding and the maternal risk of type 2 diabetes: a systematic review and dose-response meta-analysis of cohort studies. Nutr Metab Cardiovasc Dis. 2014; 24 (2): 107-15

6. Chowdhury R, Sinha B, Sankar MJ, Taneja S, Bhandari N Rollins N, Bahl R, Martines J. Breastfeeding and maternal health outcomes: a systematic review and meta-analysis. Acta Paediatr. 2015; 104 (467): 96-113.

7. WHO (World Health Organization). Global strategy for infant and young child feeding. Geneva; 2003.

8. Peres KG, Chaffee BW, Feldens CA, Flores-Mir C, Moynihan P, Rugg-Gunn A. Breastfeeding and Oral Health: Evidence and Methodological Challenges. J Dent Res. 2018; 97 (3): 251-8

9. Hartwig $\mathrm{AD}$, Romano AR, Azevedo MS. Prolonged Breastfeeding and Dental Caries In Children In the Third Year of Life. J Clin Pediatr Dent. 2019;43 (2): 91-6.

10. Torriani DD, Ferro RL, Bonow ML, Santos IS, Matijasevich A, Barros AJ, Demarco FF, Peres KG. Denta caries is associated with dental fear in childhood: findings from a birth cohort study. Caries Res. 2014; 48 (4): 263-70.

11. Moynihan P, Tanner LM, Holmes RD, Hillier-Brown F, Mashayekhi A, Kelly SAM, Craig D. Systematic Review of Evidence Pertaining to Factors That Modify Risk of Early Childhood Caries. JDR Clin Trans Res. 2019;4 (3): 202-16.

12. Fernandes IB, Pereira TS, Souza DS, Ramos-Jorge J, Marques LS, Ramos-Jorge ML. Severity of Dental Caries ographic research. Ramos-Jorge ML and Fernandes IB are responsible for all aspects of the study and writing of the article. All authors approved the final version the article.

and Quality of Life for Toddlers and Their Families. Pediat Dent. 2017; 39: 118-23.

13. Brazil. Ministry of Health. Database of the Unified Health System-DATASUS, SI-PNI - Information System of the National Immunization Program. Available at:http://pni.datasus.gov.br/consulta polio_13_selecao.asp? enviar $=\mathrm{ok} \&$ sel $=$ vacinometro\&faixa $=$ todos $\&$ grupo $=$ todos $\&$ $\mathrm{uf}=\mathrm{MG}$.

14. Ismail AI, Sohn W, Tellez M, Amaya A, Sen A, Hasson H, Pitts NB. O Sistema Internacional de Detecção e Avaliação da Cárie (ICDAS): um sistema integrado sistema para medir a cárie dentária. Comunidade Dent Oral Epidemiol. 2007 Jun; 35 (3): 170-8.

15. Tuma, RCFB, Costa HM, Schmitz BAS. Anthropometric and dietary evaluation of preschoolers in three day care centers in Brasília, Federal District. Rev Bras Saúde Mater Infant. 2005; 5 (4): 419-28.

16. Peres KG, Nascimento GG, Peres MA, Mittinty MN, Demarco FF, Santos IS, Matijasevich A, Barros AJD. Impact of Prolonged Breastfeeding on Dental Caries: A Population-Based Birth Cohort Study. Pediatrics. 2017; 140 (1): e20162943

17. Chaffee BW, Feldens CA, Rodrigues PH, Vítolo MR. Feeding practices in infancy associated with caries incidence in early childhood. Community Dent Oral Epidemiol. 2015; 43 (4): 338-48.

18. Bowen WH, Lawrence RA. Comparison of the cariogenicity of cola, honey, cow milk, human milk, and sucrose. Pediatrics. 2005; 116 (4): 921-6

19. de Mazer Papa AM, Tabchoury CP, Del Bel Cury AA, Tenuta LM, Arthur RA, Cury JA. Effect of milk and soybased infant formulas on in situ demineralization of human primary enamel. Pediatr Dent. 2010; 32 (1): 35-40.

20. Signori C, Hartwig AD, Silva-Júnior IFD, Correa MB, Azevedo MS, Cenci MS. The role of human milk and sucrose on cariogenicity of microcosm biofilms. Braz Oral Res. 2018; 32:e109.

21. Poskitti EME, Stewart L. 2017. Infancy childhood and adolescence. In: Geissler C, Powers H, editors. Human nutrition. 13th ed. Oxford (UK): Oxford University Press, p. $311-336$

22. Nakayama, Yoshimi; Mori, Mitsuru. Association between nocturnal breastfeeding and snacking habits and the risk of early childhood caries in 18- to 23-month-old Japanese children. Journal of epidemiology, 2015; 25 (2): 142-7.

23. Leong PM, Gussy MG, Barrow SY, de Silva-Sanigorski A, Waters E. A systematic review of risk factors during first 
year of life for early childhood caries. Int JPaediatr Dent. 2013; 23 (4): 235-50

24. Piva F, Pereira JT, Luz PB, Hashizume LN, Hugo FN Araujo FB. A Longitudinal Study of Early Childhood Caries and Associated Factors in Brazilian Children. Braz Dent J. 2017; 28 (2): 241-8.

25. Duijster D, de Jong-Lenters M, de Ruiter C, Thijssen J, van Loveren C, Verrips E. Parental and family-related influences on dental caries in children of Dutch, Moroccan and Turkish origin. Community Dent Oral Epidemiol. 2015; 43 (2): 152-62.

26. Levin KA, Currie C. Adolescent toothbrushing and the home environment: sociodemographic factors, family relationships and mealtime routines and disorganisation. Community Dent Oral Epidemiol. 2010; 38 (1):10-8.

27. Rai NK, Tiwari T. Parental Factors Influencing the Development of Early Childhood Caries in Developing Nations: A Systematic Review. Front Public Health. 2018; (6): 64.
28. Armfield JM, Spencer AJ, Roberts-Thomson KF, Plastow $\mathrm{K}$. Water fluoridation and the association of sugar-sweetened beverage consumption and dental caries in Australian children. Am J Public Health. 2013 Mar;103(3):494-500.

29. Rothen M, Cunha-Cruz J, Zhou L, Mancl L, Jones JS, Berg $\mathrm{J}$; Northwest PRECEDENT network. Oral hygiene behaviors and caries experience in Northwest PRECEDENT patients. Community Dent Oral Epidemiol. 2014; 42 (6): 526-35

30. Ha DH, Spencer AJ, Peres KG, Rugg-Gunn AJ, Scott JA, Do LG. Fluoridated Water Modifies the Effect of Breastfeeding on Dental Caries. J Dent Res. 2019; 98 (7): 755-62.

Received on February 7, 2020

Final version presented on December 11, 2020

Approved on December 30, 2020 